\title{
O ser humano cultivado (pepaideumenos) em Aristóteles
}

Lucas Angioni

Universidade Estadual de Campinas

\section{Resumo}

Discuto a noção de educação ou cultura (paideia) envolvida na figura do ser humano cultivado (pepaideumenos), que Aristóteles apresenta no início do tratado As Partes dos Animais e em algumas outras passagens. A competência do ser humano cultivado o habilita a avaliar certo aspecto das explicações propostas em um dado domínio, sem requerer dele um conhecimento determinado sobre o assunto específico do mesmo domínio. Examino de que modo essa competência é possível e como ela se articula a outras habilidades críticas que Aristóteles geralmente associa à ciência do ser enquanto ser.

Palavras-chave: Educação; Cultura; Paideia; Explicação científica; Competência crítica; Epistemologia das virtudes.

\begin{abstract}
I discuss the notion of education or educatedness (paideia) involved in the 'educated human being' (pepaideumenos), which Aristotle presents at the beginning of his Parts of Animals and a few other passages. The competence of educated human beings makes them able to evaluate some aspects of the explanations in a given domain without having a determinate knowledge about the specific subject-matter in that domain. I examine how such a competence is possible and how it is related to other critical abilities which Aristotle usually ascribes to the science of being qua being.
\end{abstract}

Keywords: Educatedness; Culturedness; Paideia; Scientific Explanation; Critical competence; Virtue epistemology.

Filosofia e Educação [RFE] - Volume 9, Número 1 - Campinas, SP

Fevereiro-Maio de 2017 - ISSN 1984-9605 - p. 165-196 


\section{Introdução}

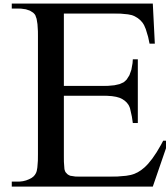

ducação em Aristóteles é um tema muito rico. Aristóteles não escreveu nenhum tratado sobre educação, em nenhum sentido da palavra (em grego, "paideia”). Não obstante, há pelo menos cinco aspectos em que o tema merece consideração meticulosa. (1) A educação, entendida como processo educacional curricular, é peça importante na formação do cidadão, em qualquer constituição. Aristóteles dedica bastante atenção a isso em sua Política. (2) Aristóteles usa o ato de ensinar como exemplo em uma discussão metafísica bem abstrata, quando discute a distinção entre a atividade daquilo que move e a atividade do que é movido (Física III.3, 202b13-21ss.). Aristóteles diz que, sob certo aspecto, a atividade pela qual o professor ensina e a atividade pela qual o discípulo aprende são uma única e mesma atividade (cf. 202b16-21). Aristóteles certamente não nega que professor e discípulo sejam dois indivíduos diferentes, cada qual com seu itinerário e seus episódios mentais intransferíveis. $\mathrm{O}$ que ele quer dizer, porém, é que ambas as atividades, a do professor e a do discípulo, têm as mesmas condições de sucesso e efetividade: só se pode dizer que uma atingiu seu término e sua compleição quando a outra também atinge sua própria compleição. (3) Embora Aristóteles não fale explicitamente de educação em sua epistemologia e em sua filosofia da ciência, nos Segundos Analíticos, temos lá todos os elementos para dizer que o processo educacional só se completa efetivamente quando o aluno compreende as razões, tanto no terreno teórico como no terreno prático. Não basta aprender que um corpo de proposições $p_{l}, \ldots p_{n}$, é verdadeiro e consistente, o aluno deve também compreender a razão apropriada que faz cada uma dessas proposições ser verdadeira. No terreno ético, não basta aprender que tais e tais ações são as corretas, é preciso compreender as razões morais que as fazem corretas. (4) Outro ponto interessante é a tese de Aristóteles sobre como nós aprendemos

Filosofia e Educação [RFE] - Volume 9, Número 1 - Campinas, SP Fevereiro-Maio de 2017 - ISSN 1984-9605 - p. 165-196 
a ser bons no terreno ético. A educação do agente moral, para Aristóteles, é um processo complexo: pela habituação na prática de certas ações, somada ao entendimento progressivo das razões para agir, o objetivo é levar o agente a sentir prazer na prática das ações corretas e a sentir incômodo, senão dor mesmo, na prática de ações incorretas. O resultado desse processo é chamado de "virtude moral", mas o desgaste da palavra "virtude" em nosso vernáculo, bem como em outras línguas contemporâneas, deixa escapar o ponto mais importante: a virtude moral é a aptidão - ou mesmo a competência, consolidada por treino e exercício - pela qual sabemos agir bem, considerados todos os fatores moralmente relevantes nas circunstâncias em que agimos. (5) Aristóteles também fala em "educação" (paideia) para referir-se ao resultado de uma formação cultural superior e abrangente: a "educação" ou "formação" (paideia), nesse sentido, é a competência consolidada no "ser humano educado ou cultivado" (pepaideumenos), que detém posição de destaque em sua aptidão crítica para apreciar e julgar os mais variados assuntos.

Não caberia considerar todos esses cinco aspectos em um único artigo. Minha escolha, neste artigo, é o último aspecto: a paideia como competência conquistada pelo ser humano cultivado e formado segundo um currículo superior. É aqui que vemos a opinião de Aristóteles sobre os mais altos desígnios e as mais altas ambições que a educação pode almejar, ao menos do ponto de vista epistemológico.

\section{Paideia e o pepaideumenos}

No início de As Partes dos Animais, Aristóteles emprega o termo "paideia" para referir-se a um tipo de habilitação ou competência pela qual alguém é reconhecido como tendo certo domínio sobre um assunto. ${ }^{1} \mathrm{O}$ termo "paideia" em Grego Clássico pode ser empregado de vários modos, assim como

1 Sobre a noção de habilitação ou competência, ver nota seguinte.

Filosofia e Educação [RFE] - Volume 9, Número 1 - Campinas, SP

Fevereiro-Maio de 2017 - ISSN 1984-9605 - p. 165-196 
nosso termos "educação" e "cultura" - que, em princípio, são boas traduções para "paideia". Em certos contextos, "educação" remete ao resultado final de um processo de instrução e treinamento pelo qual o educando adquire uma competência específica. Por exemplo, podemos dizer que "Fulano não tem educação suficiente para lidar com esse problema", quando ele não atingiu o grau de competência requisitado para lidar com os problemas em questão. Também empregamos o termo "cultura" em contextos semelhantes, quando dizemos, por exemplo, que "Fulano não tem cultura para resolver essa questão". O sentido captado por esse emprego do termo "cultura" é o que está presente também quando Aristóteles usa, nesta passagem, o termo "paideia" - o qual traduzi como "cultura":

No que concerne a qualquer estudo e investigação - de modo semelhante para os mais baixos e para os mais valiosos -, há claramente dois modos de habilitação; um deles é acertado denominar conhecimento do assunto, o outro, como que uma certa cultura" (639a1$4) .^{2}$

2 A tradução é minha, mas com várias modificações em relação à que publiquei em Angioni 1999a. Cumpre destacar a tradução do termo "hexis" por "habilitação". Quando fiz essa escolha de tradução em 1999, colegas pedantes objetaram que "habilitação é a carteira de motorista" (ao que respondi: "e identidade - outro grande conceito da metafísica ocidental - é o RG"). Causa confusão o fato de Aristóteles usar o mesmo termo "hexis" de vários modos, por exemplo, no sentido mais fraco de "condição física", no sentido de "disposição" etc. (Aristóteles, no entanto, como todos nós, usa quase todos os termos de vários modos). Mas, neste contexto de As Partes dos Animais, bem como em muitos outros, "hexis" guarda uma relação clara com o uso do verbo "echein" como auxiliar no sentido de "ter poder de, conseguir", bem como capta noção bem mais estrita que a de mera capacidade: hexis é a capacidade (usualmente adquirida e consolidada por treino controlado) pela qual somos aptos e hábeis em uma determinada tarefa - por exemplo, a nossa habilitação para dirigir (para retomar a anedota de 1999), ou a nossa competência em dar aulas sobre determinado assunto. Em 1999, não tinha ainda tido contato com a corrente de epistemologia contemporânea centrada em Ernst Sosa, que identifica o conceito de "virtude" como básico. O termo "virtude" (assim como "virtue" em inglês) encontra-se desgastado por sua aplicação exclusiva ao domínio moral, mas Sosa (2006) o utiliza do modo como encontramos o conceito na filosofia grega e em Aristóteles: arete ("virtude") é a excelência pela qual somos bons em determinada prática (cf. 1106a15-21), ou seja, é a competência, consolidada pelo exercício refletido e respaldada pelas razões corretas, pela qual temos o desempenho apropriado em

Filosofia e Educação [RFE] - Volume 9, Número 1 - Campinas, SP

Fevereiro-Maio de 2017 - ISSN 1984-9605 - p. 165-196 
O primeiro modo pelo qual alguém se encontra habilitado a falar sobre um assunto é o que traduzi como "conhecimento do assunto". Não há dúvida de que essa expressão remete àquilo que constitui o objeto do tratado $\mathrm{Se}$ gundos Analíticos, isto é, o conhecimento científico de um dado domínio. Há inúmeras questões importantes sobre esse tipo de competência, mas o que nos interessa neste artigo é o segundo tipo, que designei como "uma certa cultura". Sobre esse tipo de competência, Aristóteles não escreveu nenhum tratado, mas apenas umas poucas linhas, aqui na introdução a sua filosofia da zoologia, bem como na Ética a Nicômaco. ${ }^{3}$ As sentenças seguintes no texto de Aristóteles elucidam em que consiste essa "certa cultura", ao identificar capacidades específicas pelas quais se distingue o "ser humano cultivado", isto é, o ser humano que possui essa "certa cultura":

é próprio de alguém cultivado ser capaz de discernir de maneira acertada e segundo o modo apropriado o que corretamente ou não corretamente propõe aquele que tenta explicar. Pois é alguém desse tipo que julgamos em geral ser cultivado, isto é, julgamos que ser cultivado é ser capaz de fazer isso que foi mencionado (639a4-8).

“Aquele que tenta explicar" é aquele que propõe alguma tese ou explicação em um dado domínio. Aristóteles atribui ao "ser humano cultivado" a capacidade - ou, mais especificamente, a competência, uma aptidão efetiva e consolidada pelo acerto na prática - de julgar, avaliar ou discernir

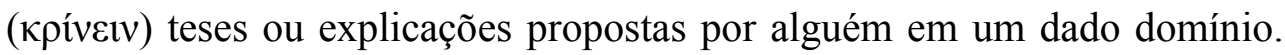
No entanto, é claro que o "ser humano cultivado" não se confunde com o

um dado domínio. "Hexis" em 639a2 poderia ter sido traduzido por "virtude" no sentido em que Sosa emprega o termo.

3 Ética a Nicômaco 1094b23-1095a2. Trataremos desse texto mais adiante.

Filosofia e Educação [RFE] - Volume 9, Número 1 - Campinas, SP

Fevereiro-Maio de 2017 - ISSN 1984-9605 - p. 165-196 
"conhecedor do assunto": de outro modo, a distinção com a qual Aristóteles começa seria vazia e despropositada. Com certeza, o conhecedor do assunto também é alguém que possui a competência de julgar (avaliar, discernir) teses e explicações sobre o assunto de seu domínio. Por isso, é claro que Aristóteles supõe haver uma distinção bem determinada entre, de um lado, o juízo competente do conhecedor do assunto e, de outro lado, o juízo competente do ser humano cultivado. Essa distinção repousa sobre o objeto exato do juízo competente de cada um: não são as mesmas coisas que, precisamente, cada um julga e avalia. Uma vez compreendida essa distinção, será mais fácil compreender também certas peculiaridades do modo pelo qual o ser humano cultivado julga e avalia.

Comecemos pelo primeiro ponto: o que, precisamente, cada um julga e avalia? De um lado, dado que o "conhecedor do assunto" é aquele que tem conhecimento científico de um dado domínio, nos moldes expostos nos $\mathrm{Se}$ gundos Analíticos, é claro que ele julga, entre outras coisas, dois fatores proeminentes. Em primeiro lugar, o "conhecedor do assunto" está na posição de discernir se são verdadeiras ou falsas as proposições básicas de um dado domínio, isto é, aquelas proposições que descrevem os fenômenos e desse modo assentam os explananda do domínio. ${ }^{4}$ Se alguém, por exemplo, disser que os bovinos têm seis cavidades estomacais, o "conhecedor do assunto" está na posição de dizer, pela sua familiaridade com o objeto, que tal proposição é falsa. Em segundo lugar, o "conhecedor do assunto" está em condições de avaliar se são apropriadas ou não as explicações que se propõem para os fenômenos de um dado domínio. Se alguém, por exemplo, disser

4 Doravante, usarei a expressão "proposições básicas" para designar as proposições que descrevem os fatos a serem explicados em um dado domínio. No vocabulário de Aristóteles, trata-se daquelas proposições que estabelecem que ("hoti") - em contraste com estabelecer por que - um dado sujeito tem tal e tal atributo. Cf. Segundos Analíticos II.1-2, especialmente 89b23-90a23. Sobre essa distinção, ver Charles 2000, p. 67-71, Bronstein 2016, p. 74-6.

Filosofia e Educação [RFE] - Volume 9, Número 1 - Campinas, SP

Fevereiro-Maio de 2017 - ISSN 1984-9605 - p. 165-196 
que a coluna vertebral é articulada em várias partes porque, no processo de geração do animal, diversas torções a quebraram (cf. 640a19-22), o "conhecedor do assunto" também está na posição de dizer que essa tentativa de explicação não é apropriada. Em ambos os casos, o critério que o "conhecedor do assunto" assume em sua avaliação é seu próprio conhecimento dos fatos no domínio em questão. Por estudar o assunto e ter familiaridade com as coisas mesmas desse domínio, o "conhecedor do assunto" tem a capacidade de julgar se são verdadeiras ou falsas as proposições que descrevem os fenômenos, bem como a capacidade de julgar se certas tentativas de explicação são adequadas ou não. É bom ressaltar que seu juízo competente depende de como as coisas são, mas de um modo bem preciso. É porque os estômagos bovinos são como são que o "conhecedor do assunto" sabe julgar as proposições a respeito deles. É a esse fato específico da natureza - os estômagos bovinos serem como são - que o "conhecedor do assunto" apela para emitir seu juízo. E o mesmo se dá, basicamente, quando ele julga uma proposta de explicação. ${ }^{5}$ Ele apela para o fato de que a espinha dorsal (e seu processo de formação) é tal como ela é. Veremos que isso é importante para o contraste com o "ser humano cultivado".

Por outro lado, o que, precisamente, o "ser humano cultivado" julga e avalia? O objeto preciso de seus juízos e avaliações não pode ser o mesmo que compete ao "conhecedor do assunto". Aristóteles nos dá alguma informação a esse respeito algumas linhas mais adiante:

é evidente que, também na investigação sobre a natureza, é preciso haver tal tipo de regras, por referência às quais se pode apreciar o modo

5 Em relação às explicações, pode haver alguma complicação, mas ela não afeta meu ponto neste artigo. Tratei dessas complicações em Angioni 2014, p. 75-83. Não é claro como Aristóteles julga a correção de explicações: nelas, há em geral três proposições básicas envolvidas, mas é pouco claro se a relação propriamente causal-explanatória seria um fato específico à parte dos fatos expressos nas proposições básicas.

Filosofia e Educação [RFE] - Volume 9, Número 1 - Campinas, SP

Fevereiro-Maio de 2017 - ISSN 1984-9605 - p. 165-196 
daquilo que se explica, à parte do "como se tem a verdade, se é assim ou de um outro modo" (639a12-15).

Voltaremos a essa passagem mais tarde, mas, por enquanto, o que quero explorar é o trecho em itálico. Aristóteles está a descrever a competência que atribui ao "ser humano cultivado". Aristóteles diz que o juízo do "ser humano cultivado" avalia o modo daquilo que se pretende explicar (ou expor) em um dado domínio, mas sem entrar na questão da verdade. Como pode ser assim? Voltemos aos mesmos exemplos usados acima. Se alguém propõe que os bovinos têm seis cavidades estomacais, o "ser humano cultivado" está em condições de apreciar o "modo" dessa proposição, à parte de seu valor de verdade? Aristóteles deixa claro que o "ser humano cultivado" não está na posição de dizer se tal proposição é verdadeira ou não, pois ele não tem o conhecimento do assunto. $\mathrm{O}$ que lhe resta, então, para julgar? Resta-lhe julgar "o modo daquilo que se explica", de acordo com certas regras. Para entender o que isso significa, é muito mais sensato, bem como coerente com o que Aristóteles diz aqui e alhures, considerar que esse "modo" não é uma propriedade de proposições isoladas - ou seja, não é uma propriedade que estivesse no mesmo nível da propriedade de ser verdadeira ou ser falsa, aplicada a proposições básicas isoladas, como "os estômagos bovinos tem seis cavidades". Isso sugere que, a rigor, o escopo a que se aplica a competência do "ser humano cultivado" não é nunca uma única proposição isolada, mas é sempre um conjunto articulado de proposições - e isso se coaduna com a expressão empregada por Aristóteles, “deiknumenon”. Em vários contextos, o verbo “deiknumi” em suas variadas formas é empregado por Aristóteles para referir-se a uma proposta de explicação em um dado domínio. E uma proposta de explicação relaciona ao menos duas proposições 
básicas. ${ }^{6}$ É também provável que o verbo “deiknumi” seja empregado para referir-se ao modo pelo qual uma exposição, isto é, uma obra, se desenvolve. ${ }^{7}$ Esses dois empregos do verbo são propícios para entender o que Aristóteles atribui ao "ser humano cultivado".

Por um lado, o "ser humano cultivado" está na posição de avaliar se uma proposta de explicação está adequada ou não a uma determinada regra reconhecida no domínio. Voltemos ao exemplo da espinha dorsal. Quando Empédocles propõe explicar a composição da espinha dorsal pelas supostas vicissitudes em seu processo de formação (cf. 640a19-22), o "ser humano cultivado" está na posição de rejeitar o modo dessa explicação, apelando para uma regra aceita no domínio. O "ser humano cultivado" dirá que a explicação de Empédocles apela tão somente a causas materiais e eficientes, cuja conjunção parece dar-se por mero acaso. Enquanto tal, essa proposta de explicação fere a regra de que explicações de fenômenos pertinentes ao domínio da morfologia animal deve levar em conta, preponderantemente, causas formais e finais - isto é, qual é a função que a espinha dorsal cumpre, por ser composta do modo como é composta. ${ }^{8}$ E tudo que Aristóteles diz parece sugerir que o "ser humano cultivado" pode exercer essa competência mesmo ser ter o conhecimento específico no domínio da morfologia animal. Essa competência, no entanto, parece ser puramente crítica, isto é, tem por

6 Bem entendido, meu ponto não depende do plural “deiknumenon", como se essa expressão envolvesse, por estar no plural, a relação entre explanandum e explanans. Alguém poderia objetar que o plural é distributivo e que o alvo da expressão seria tão somente a con clusão de cada argumento explanatório (uma paráfrase disso poderia ser: "o modo das conclusões que, a cada vez, se quer explicar"). Eu posso aceitar que o plural seja distributivo ("cada conclusão que, a cada vez, se quer explicar"). Meu ponto é que a conclusão desses argumentos está sob o juízo do ser humano cultivado justamente enquanto explanandum (e não quanto a seu valor de verdade) e, por isso, tal juízo não pode ignorar qual é a proposição alegada como explanans - de modo que o objeto do juízo, a rigor, é a relação entre a proposição a ser explicada e a proposição explanatória. Cf. Irwin 1988, p. 27-29 (o ser humano cultivado julga "the method of proof").

7 Essa sugestão não foi considerada por ninguém, até onde sei.

8 Cf. Lennox 2001, p. 131-3, Lennox 2010, p.66-67; Angioni 1999, p. 58-61; para outra opinião, ver Carbone 2016, p. 9-10.

Filosofia e Educação [RFE] - Volume 9, Número 1 - Campinas, SP

Fevereiro-Maio de 2017 - ISSN 1984-9605 - p. 165-196 
função avaliar explicações propostas por outras pessoas. Suponhamos que nosso "ser humano cultivado" nunca tenha praticado dissecção, nunca tenha lido com cuidado um livro de anatomia, enfim, tenha uma noção apenas muito vaga de como a espinha dorsal dos animais é em geral constituída. Mesmo nesse estado de considerável ignorância em relação à espinha dorsal, o "ser humano cultivado" é capaz de emitir um juízo sobre a adequação de uma proposta de explicação sobre a mesma. A adequação, neste caso, não se reduz ao valor de verdade de sentenças básicas no domínio - pois a verdade ou falsidade dessas sentenças básicas descritivas é estabelecida por observação empírica, a qual compete ao conhecedor do assunto (cf. Primeiros Analíticos I.30). A adequação em pauta não diz respeito a saber se é verdade que a espinha dorsal é, de fato, assim como propõem. A adequação em pauta tem por foco o acordo ou desacordo entre a proposta de explicação e uma regra explanatória aceita no domínio. O "ser humano cultivado" tem capacidade de emitir juízos sobre essa adequação porque ele foi bem educado a esse respeito - diríamos, hoje, que ele fez um bom curso de filosofia da ciência, mesmo sem aprender os conteúdos específicos das ciências.

No entanto, é importante ressaltar que seu juízo competente também depende de como as coisas são (pois, no quadro do realismo de Aristóteles, as regras em questão não podem estar desvinculadas da realidade $)^{9}$, mas depende mais especificamente das regras explanatórias aceitas no domínio em questão. Há um fato especifico na natureza: a espinha dorsal ser como ela é. No entanto, não é a esse fato específico que o "ser humano cultivado" apela para emitir seu juízo. Ele apela para seu conhecimento de que uma dada regra explanatória é aceita no domínio em questão. Esse regra explanatória, no entanto, está longe de ser pura convenção entre especialistas ou pura opinião

9 É importante ressaltar esse ponto, pois, de outro modo, poderia parecer que estou do lado de Nussbaum 1986, atribuindo a Aristóteles uma espécie de realismo internalista. (Concordo com as críticas de Cooper 1988 contra Nussbaum 1986).

Filosofia e Educação [RFE] - Volume 9, Número 1 - Campinas, SP

Fevereiro-Maio de 2017 - ISSN 1984-9605 - p. 165-196 
dialética, pois também está ancorada nos fatos. ${ }^{10}$ Como veremos adiante, na próxima seção, as regras de que dependem os juízos do ser humano cultivado dependem das coisas mesmas, mas em um nível mais abstrato de generalidade.

Antes de explorar melhor esse ponto - que ficará bem mais claro após apreciação de trechos da Metafísica, na seção seguinte deste artigo -, observo que uma interpretação similar pode ser igualmente adotada se a expressão "deiknumenon" for entendida como designando uma dada exposição, com seus meandros e volteios metodológicos - por exemplo, a exposição que se segue, nos livros seguintes de As Partes dos Animais. ${ }^{11}$ De fato, Aristóteles parece estar preocupado com o método a seguir na obra que o leitor lerá em seguida: ao falar sobre as partes que compõem os animais, a exposição deveria focar os atributos partilhados em comum por vários tipos de animais, ou deveria sempre ter o foco nas espécies últimas? Suponha que o assunto da exposição seja o que hoje chamamos de sistema digestivo. Aristóteles pergunta: a exposição deve primeiro ater-se aos elementos partilhados

10 Estou longe de propor que o ser humano cultivado, ao apelar a regras de um dado domínio, se confunde com o debatedor dialético que apela aos endoxa ("as opiniões reputadas"). Muitos talvez ficariam felizes com essa equação, como Le Blond 1945, p. 130 (ver crítica em Lennox 2001, p. 120). Há relações importantes a serem exploradas entre paideia e dialética, mas uma não se reduz a outra (cf. Irwin 1988, 27-29, 145, 179-180). O dialético enquanto tal não tem nenhuma preocupação com o suposto respaldo dos endoxa nos fatos mesmos (ver Mendonça 2014). Já o ser humano cultivado assume certas regras como critério de sua apreciação crítica porque, dado o estado da questão, aquelas regras são as regras aceitas pelos conhecedores do assunto, e estes últimos só as aceitam porque entendem que elas explicam bem os fatos tal como estes se apresentam na realidade. Assim, o ser humano cultivado assume certas regras porque, em última instância, acredita (respaldado pelos conhecedores do assunto) que elas condizem com a realidade. Os conhecedores do assunto têm maestria sobre essas regras (sabem usá-las, aplicá-las, foram seus proponentes originais etc.). Já o ser humano cultivado as conhece em certo sentido porque fez um bom curso de filosofia da ciência, mas não tem maestria sobre elas.

11 Essa sugestão de interpretação para o problema metodológico formulado em 639a15-b5 não foi levada em conta nem por Lennox 2001, p. 121-2, nem por Balme 1992, p. $72-3$ (cf. Lennox 1987, p. 114-5; Lennox 2010, p. 67-69). Aristóteles pode ter motivações mais profundas para esse problema no terreno da metafísica, da epistemologia e da teoria da causalidade, mas nem por isso se pode descartar uma interpretação puramente pragmática do mesmo.

Filosofia e Educação [RFE] - Volume 9, Número 1 - Campinas, SP

Fevereiro-Maio de 2017 - ISSN 1984-9605 - p. 165-196 
em comum pelo maior número de gêneros animais, para depois atentar às especificidades? Ou deveria já de início se ater a cada espécie e fazer uma exposição do sistema digestivo espécie por espécie? Se a segunda opção fosse seguida, a obra ficaria repetitiva e tediosa, sem nenhuma vantagem informativa (cf. 639a23-29; 644a34-b1). O nosso "ser humano cultivado" seria capaz de notar isso, mesmo sem ter nenhum conhecimento sobre o aparelho digestivo dos animais. Ele seria capaz de dizer, com razão: "que porcaria de livro chato!".

\section{O pepaideumenos e a ciência do ser enquanto ser}

Vimos que o ser humano cultivado, ao avaliar pretensões de explicação em um dado domínio, não se atém ao valor de verdade das proposições básicas do domínio, ou seja, o "ser humano cultivado" não nutre a competência específica pela qual pudesse detectar proposições falsas sobre, por exemplo, estômagos bovinos ou espinhas dorsais. Vimos que seu modo de julgar se atém antes a regras aceitas para a explicação e para a exposição teórica em um dado domínio. Mas há algo mais a respeito de seu modo de julgar?

Em 639a5, Aristóteles diz que o "ser humano cultivado" é capaz de

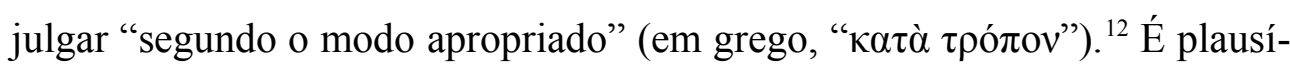
vel dizer que esse modo apropriado tem alguma relação com o modo pelo qual argumentos devem ser apresentados. Em primeiro lugar, argumentos que pretendem explicar algo em dado domínio devem ater-se a regras explanatórias mais específicas daquele domínio - por exemplo, explicações no

12 À primeira vista, a expressão grega parece ser mais bem traduzida como "pelo modo", ou seja, o adjetivo "apropriado", na minha tradução, parece um intruso, oriundo da minha imaginação. No entanto, quando um jogador de futebol sofre uma contusão em uma jogada e diz, do adversário que o atingiu, que "ele me pegou de jeito", o que ele quer dizer é que o adversário o atingiu do jeito apropriado para causar a contusão. Assim, por boas razões ligadas ao contexto (imediato e amplo), creio que "kata tropon" em 639a5 quer dizer "do modo apropriado".

Filosofia e Educação [RFE] - Volume 9, Número 1 - Campinas, SP

Fevereiro-Maio de 2017 - ISSN 1984-9605 - p. 165-196 
domínio da zoologia devem pautar-se pela primazia das causas finais sobre as causas puramente materiais (cf. 640b4-29). ${ }^{13}$ Em segundo lugar, argumentos que pretendem apresentar explicações de modo sistemático em um dado domínio devem seguir certos parâmetros específicos de organização por exemplo, ir do mais geral ao mais particular para evitar repetições desnecessárias, mas ater-se ao particular quando o assunto assim exige (cf. 644a34-b7). Em terceiro lugar, argumentos que pretendem explicar algo em dado domínio devem ser deduções válidas - ou seja, a conclusão deve impor-se como conseqüência lógica das premissas. As duas primeiras condições parecem claramente contempladas por Aristóteles, quando ele diz o seguinte:

no entanto, consideramos o ser humano cultivado como alguém que, sendo um só, é capaz de julgar a respeito de tudo, por assim dizer, ao passo que o outro [sc. o conhecedor do assunto] se ocupa com um domínio determinado; mas é que há outro tipo de ser humano cultivado, semelhante ao primeiro, mas em relação a algum domínio particular. $(639 \mathrm{a} 8-12)^{14}$

O ser humano cultivado em algum domínio particular parece ser exatamente aquele que se ocupa de regras específicas para a explicação e a exposição, como as que Aristóteles começa a apresentar em 639a15, pertinentes ao estudo da morfologia animal. Esse ser humano cultivado especificamente em um domínio particular tem a competência de discernir se argumentos estão de acordo com as duas condições que há pouco mencionamos. Já no que concerne à terceira condição, Aristóteles nada diz de modo explí-

13 Lennox 2001, p. 131-4, 136-7; Balme 1992, p. 87; Angioni 1999, p. 66-72.

14 Aqui, minha tradução difere bastante da que se encontra em Angioni 1999a. Discussão com vários pesquisadores melhorou minha compreensão dessa passagem.

Filosofia e Educação [RFE] - Volume 9, Número 1 - Campinas, SP

Fevereiro-Maio de 2017 - ISSN 1984-9605 - p. 165-196 
cito em As Partes dos Animais. A competência atinente a essa terceira condição requer que o "ser humano cultivado" tenha alguma formação básica em lógica: ele deve ter competência para discernir se um argumento é válido ou não, bem como competência para avaliar certas proposições cuja verdade parece depender de fatores que Aristóteles chama de "analíticos" (porque são coisas que ele considerou nos tratados que foram batizados de “Analíticos"), mas que podemos chamar de lógico-formais. Essa sugestão, creio, se confirma em duas passagens da Metafísica.

A primeira que nos compete considerar é a seguinte:

por falta de formação [apaideusia], alguns exigem que também isso [sc. o Princípio da Não-Contradição] seja demonstrado; de fato, é falta de formação não reconhecer de que coisas é preciso procurar demonstração e de que coisas não é preciso; é que, em suma, é impossível haver demonstração de absolutamente tudo (pois se prosseguiria ao infinito) (1006a5-9)..$^{15}$

"Falta de formação" traduz "apaideusia", termo que é constituído pelo alfa privativo e a mesma raiz de "paideia". ${ }^{16}$ A rigor, os dois termos podem ser usados como contrários: enquanto "paideia" pode designar a habilitação de um ser humano cultivado, "apaideusia" designa exatamente a falta de tal habilitação. Aristóteles identifica como apaideusia a exigência (feita por alguns de seus adversários) de que também fosse demonstrado o Princípio da Não-Contradição. Não nos cabe entrar nos detalhes dessa discussão espi-

15 Tradução minha, com modificações em relação a Angioni 2006, p. 173.

16 Outras opções de tradução seriam "falta de cultura" e "falta de educação": esta última expressão, porém, é claramente inadequada ao contexto (pois se solidificou, ao menos em Português brasileiro, como denominação da falha comportamental do sujeito que não segue normas de polidez etc.), já a primeira é aplicada sobretudo em contextos que dizem respeito ao gosto estético; por isso, preferi "falta de formação" para o contexto em pauta.

Filosofia e Educação [RFE] - Volume 9, Número 1 - Campinas, SP

Fevereiro-Maio de 2017 - ISSN 1984-9605 - p. 165-196 
nhosa. ${ }^{17}$ Basta-nos notar o seguinte: Aristóteles julga que tal princípio não pode ser demonstrado - isto é, ainda que um argumento possa estabelecê-lo como conseqüência necessária de certas premissas, nenhum argumento poderia estabelecer que sua verdade se fundamenta na verdade de outras proposições mais básicas do que ele. ${ }^{18}$ Mas o mais importante para meus propósitos é a tese mais geral que Aristóteles aplica ao Princípio da Não-Contradição. Para Aristóteles, é verdadeira a proposição meta-teórica de que, em qualquer sistema demonstrativo, as séries de demonstrações não podem ir ao infinito, mas devem parar em proposições primitivas, cuja verdade não pode ser fundamentada por demonstração. Aristóteles julga ter provado essa proposição meta-teórica em Segundos Analíticos I.3 (72b18-32) e I.22 (84a30b2). ${ }^{19}$ Sua reclamação em Metafísica 1006a5-9 se dirige a adversários que, exigindo uma prova demonstrativa do Princípio da Não-Contradição, ignoram a verdade da proposição meta-teórica discutida nos Analíticos. Visto que essa exigência impertinente é identificada como caso de apaideusia, é legítimo inferir que a paideia, como contrário da apaideusia, inclui o conhecimento de que é verdadeira a proposição meta-teórica discutida nos Analíticos. A competência do "ser humano cultivado" envolve, portanto, a apreensão desse tipo de proposição meta-teórica discutida nos Analíticos. Como tal apreensão só é possível se alguém tenha previamente compreendido conceitos básicos de que ela depende, como os conceitos de argumento correto, argumento válido, proposição etc., pode-se legitimamente inferir que a competência do ser humano cultivado envolve alguma maestria sobre esses con-

17 A discussão sobre esse tópico é imensa. Ver, mais recentemente, Moreira 2015.

18 Essa distinção entre demonstrar e argumentar em favor de (ou mesmo estabelecer por meio de um argumento) pode ser encontrada em Code 1986, p. 348; Cohen 1986, p. 360-1 e Furth 1986, p. 375-6. Ver também minha posição em Angioni 1999, p. 122 (nota 2) e Angioni 2006 , p. $45-8$.

19 Para recente investigação sobre esse tópico, ver Lourenço 2013. Sobre Segundos Analiticos I.3, ver Goldin 2013.

Filosofia e Educação [RFE] - Volume 9, Número 1 - Campinas, SP

Fevereiro-Maio de 2017 - ISSN 1984-9605 - p. 165-196 
ceitos e, portanto, alguma capacidade de avaliar a validade formal de argumentos.

Um pouco antes, no mesmo livro IV da Metafisica, Aristóteles dissera algo bem elucidativo a esse respeito:

nenhum dos que pesquisam em particular põe-se a explicar algo sobre eles [sc. os princípios silogísticos] - se são verdadeiros ou não -, nem o geômetra, nem o aritmético, mas apenas alguns estudiosos da natureza, e é plausível que assim o tenham feito, pois apenas eles julgavam estudar a natureza inteira e o ente. [...] Quanto àquilo que alguns (entre os que foram mencionados) tentam estabelecer sobre a verdade, concernente ao modo pelo qual é preciso avaliá-la, fazem-no devido à falta de formação nos Analiticos." (1005a29-33; b2-5, tradução minha).

A situação que Aristóteles considera nessa passagem é a seguinte. Há princípios silogísticos (cf. 1005b7), que são usados ou aplicados por todos os cientistas particulares (ou por todos que fazem uso de argumentos), mas não compete a nenhum desses cientistas discutir a verdade sobre os mes$\operatorname{mos}^{20}$. A razão disso é que tais princípios, sendo os mais universais possíveis, dependem do ser enquanto ser, em abstrato. Quando esses princípios são aplicados, por exemplo, aos números, a verdade dessa aplicação depende do fato de que os números são seres (de um modo ou de outro), mas não depende do fato de que os números são especificamente os números que são. Do mesmo modo, quando um princípio desse tipo se aplica ao fogo por exemplo, quando se diz, por aplicação do Princípio da Não-Contradição, que "é impossível para o fogo ao mesmo tempo ser quente e não ser quente" 20 Em 1005b3, a expressão "tes aletheias" não se refere à noção abstrata de Verdade, mas à verdade dos princípios silogísticos. O artigo definido grego pode ter essa função determinante, que remete a algo já mencionado no contexto.

Filosofia e Educação [RFE] - Volume 9, Número 1 - Campinas, SP

Fevereiro-Maio de 2017 - ISSN 1984-9605 - p. 165-196 
- a verdade dessa sentença particular não depende do fato de o fogo ser o elemento natural que ele é, mas depende apenas do fato de que o fogo é um ser, em abstrato. ${ }^{21}$ Por isso, Aristóteles defende que a discussão sobre a verdade desses princípios compete ao teórico que considera o ser enquanto ser, e esse é precisamente o filósofo (cf. 1005b5-8, 11), ou, como hoje talvez chamaríamos, o metafísico. ${ }^{22}$

Alguns adversários ou antecessores, porém, tentaram explicar algo sobre os princípios silogísticos e, mais particularmente, tentaram explicar de que modo seria preciso aceitar a verdade desses princípios. Essa descrição geral do comportamento teórico dos adversários parece incluir também a atitude identificada em 1006a5-9, qual seja, buscar fundamentar a verdade dos primeiros princípios em algum princípio anterior. Mas tal descrição parece incluir também um outro tipo de procedimento. Suponha, por exemplo, que, ao aplicar princípios silogísticos às linhas (ou aos números, ou ao fogo), os adversários tenham pretendido que a verdade de tais princípios dependeria do modo de ser específico das linhas, ou seja: é porque as linhas são as linhas que são que se poderia concluir sobre elas uma predicação afirmativa universal no modo Barbara..$^{23}$ No entanto, uma conclusão afirma-

21 Do mesmo modo, a verdade da sentença "é impossível para o fogo ao mesmo tempo ser frio e não ser frio" tampouco depende do fato de o fogo ser o elemento natural que ele é. O mesmo vale para a verdade da sentença "é impossível para o fogo ao mesmo tempo ser ímpar e não ser ímpar".

22 Ver Fine 2012, especialmente p. 19-22, para uma tal caracterização contemporânea da metafísica.

23 Interpreto desse modo o argumento de Aristóteles em Metafísica 1004b5-17 (especialmente 1004b5-8) - apenas fiz pequena adaptação dos exemplos. Aristóteles fala de noções como mesmo, outro, contrário etc., e falará de princípios silogísticos apenas mais adiante, em 1005b7. No entanto, creio que o argumento de 1004b5-17 se aplica a todos os princípios que caem sob a alçada do filósofo ou metafísico. Tomemos uma sentença tal como esta: "se uma linha $A$ é diferente de uma linha $B$, então há pelo menos uma propriedade que é verdadeira de $A$, mas não de $B$ ". Os adversários de Aristóteles teriam pretendido que a verdade dessa sentença dependeria do modo de ser específico das linhas: é porque as linhas são as linhas que são que se poderia afirmar com verdade tal sentença. Aristóteles insiste que a verdade de sentenças como essa depende apenas do fato de que as linhas são seres, em abstrato.

Filosofia e Educação [RFE] - Volume 9, Número 1 - Campinas, SP

Fevereiro-Maio de 2017 - ISSN 1984-9605 - p. 165-196 
tiva universal no modo Barbara não depende de modo algum das linhas e, a rigor, não depende de nenhum conteúdo determinado a que possa ser aplicada: ela depende apenas das relações entre as formas predicativas, de acordo com fatores puramente lógicos como a quantificação das sentenças e a ordenação dos termos nas chamadas figuras silogísticas. E quem leu e compreendeu os Primeiros Analíticos tem a competência requisitada para saber disso.

Na passagem que agora examinamos, a expressão de Aristóteles é bem determinada e, por isso, informativa: em 1005b2-5, "falta de formação nos Analíticos" indica precisamente a falta das competências que dependem de uma compreensão adequada dos conceitos envolvidos nos Analíticos, tais como argumento válido, sentença predicativa, termo, quantificador etc. Aristóteles identifica nos adversários em questão uma incompetência oriunda da ignorância desses conceitos básicos - ou talvez oriunda da falta de aptidão para o uso sistemático desses conceitos. Por contraste, é lícito inferir que o ser humano cultivado nos Analíticos tem precisamente as competências que faltam nesses adversários de Aristóteles: eles dominam conceitos como o de argumento válido, proposição, predicação, termo etc.

É importante notar que, na expressão "o modo pelo qual é preciso avaliar a verdade" em Metafísica 1005b3, o verbo "avaliar" (apodechesthai) é o mesmo que aparece na passagem de As Partes dos Animais 639a12-15, quando Aristóteles menciona as "regras por referência às quais se pode apreciar [apodechesthai] o modo daquilo que se explica, à parte do 'como se tem a verdade, se é assim ou de um outro modo". O verbo "apodechesthai" quer dizer "receber", no sentido de "apreciar" (fazer uma apreciação, um juízo) ou "avaliar". ${ }^{24}$ Assim, as duas passagens compartilham da mesma

24 Há uma diferença clara no uso de "receber" nas sentenças a seguir: "o pacote foi recebido pelo destinatário?", "como o show do Caetano foi recebido pela crítica?". O emprego que Aristóteles faz de "apodechesthai" equivale apenas ao último sentido de "receber", que

Filosofia e Educação [RFE] - Volume 9, Número 1 - Campinas, SP

Fevereiro-Maio de 2017 - ISSN 1984-9605 - p. 165-196 
idéia central. O trecho de As Partes dos Animais nos permite afirmar que o "ser humano cultivado" dispõe de regras ou princípios por meio dos quais avalia certos aspectos de uma argumentação: em vez de ter aptidão para detectar proposições básicas falsas em um determinado domínio teórico (por exemplo, na zoologia), o "ser humano cultivado" é apto a avaliar se uma argumentação está de acordo com regras explanatórias aceitas no domínio em questão, bem como é apto a avaliar se uma exposição está de acordo com regras metodológicas aceitas para tal domínio. Por outro lado, a passagem Metafísica 1006a5-9 sugere que a competência do "ser humano cultivado" também envolve o conhecimento de que certas proposições meta-teóricas são verdadeiras (como a proposição de que, em qualquer sistema demonstrativo, é impossível demonstrar ao infinito etc.), de onde se segue que sua competência também envolve a aptidão para lidar com conceitos básicos, como o de argumento válido, proposição, etc. Em Metafísica 1005b2-5, Aristóteles acrescenta que o "ser humano cultivado" também conhece "o modo pelo qual é preciso avaliar a verdade" dos princípios silogísticos, ou, ao menos, em leitura mais modesta, sabe que não deve avaliar a verdade desses princípios a partir do conteúdo determinado a que se aplicam.

\section{Paideia e arquitetônica}

Pois bem: o "ser humano cultivado" tem competência para avaliar se ferramentas argumentativas foram usadas adequadamente ou não, independentemente do conteúdo a que se aplicam. O "ser humano cultivado" também sabe que a verdade dos princípios que regulam essas ferramentas não depende do conteúdo particular a que elas se aplicam. Essas duas habilitações se somam a uma certa posição arquitetônica - no sentido de que ele está em

equivale a "apreciar", "avaliar", ou, ainda mais precisamente, avaliar de acordo com critérios específicos adequados ao caso. Cf. o uso desse verbo também em Partes dos Animais $644 b 16$ (em que seu objeto direto é "methodos") e Metafísica 995a13.

Filosofia e Educação [RFE] - Volume 9, Número 1 - Campinas, SP

Fevereiro-Maio de 2017 - ISSN 1984-9605 - p. 165-196 
posição de discernir as diferenças entre diversos tipos de disciplinas, bem como o tipo de argumentação que é apropriado a cada uma. Esse ponto é claro pelo que Aristóteles diz sobre o "ser humano cultivado" na Ética a Nicômaco:

é próprio do ser humano cultivado exigir a acurácia em cada gênero na exata medida que a natureza do assunto admite. De fato, aceitar um matemático a se expressar por discursos persuasivos é claramente similar a exigir demonstrações de um orador (1094b23-27; tradução minha). ${ }^{25}$

Um matemático deve expressar-se com a clareza e a exatidão que seu assunto exige. "Expressar-se por discursos persuasivos" consiste em usar o tipo de discurso que é objeto da Retórica de Aristóteles, isto é, um discurso que, tendo por alvo a persuasão de uma audiência específica, se contenta com linhas gerais e aproximativas, em vez de delinear as particularidades pertinentes ao objeto, e se atém ao que é verossímil, em vez de se ater ao que é verdadeiro. ${ }^{26}$ Suponha um aritmético a concluir seu cálculo deste modo: "bem, provavelmente a soma de 555 e 465 é maior que mil". Ou um geômetra, arengando de modo agradável para concluir que "estes dois triângulos são provavelmente mais ou menos iguais em área". Não é isso que se espera deles (nota que Aristóteles não está falando do ensino de matemática, mas do puro exercício teórico de um conhecedor do assunto). E alguém que

25 Prefiro traduzir akribeia como "acurácia", em vez de "precisão" ou “exatidão" (que são as opções mais usadas, ver respectivamente Broadie \& Rowe 2002 e Irwin 1999), porque tal termo - assim me parece - contempla melhor os dois elementos envolvidos: a exatidão na descrição dos fatos, e o acerto na identificação das causas. Sobre a noção de "acurácia" (akribeia) e seus variados usos em Aristóteles, ver Lesher 2010.

26 Que fique claro que Aristóteles não menospreza a arte oratória em si mesma, que é objeto de sua obra Retórica. O recurso ao verossímil e todas as demais ferramentas da retórica constituem uma competência digna. O problema é usá-la em contextos em que ela não é pertinente.

Filosofia e Educação [RFE] - Volume 9, Número 1 - Campinas, SP

Fevereiro-Maio de 2017 - ISSN 1984-9605 - p. 165-196 
lhes aceitasse esse tipo de discurso estaria exigindo o grau de acurácia que não é o adequado ao objeto em questão.

Por outro lado, o orador é quem por definição deve contentar-se com discursos persuasivos, pois seu objetivo é obter a aprovação da audiência. Ele deve, portanto, adaptar suas ferramentas discursivas ao nível intelectual da audiência, o que muitas vezes significa limitar-se a discursos que falam de algo em linhas gerais e aproximativas, atendo-se ao verossímil em vez de se ater ao que é estritamente verdadeiro (cf. Retórica $1355 \mathrm{a} 22$ ss.). Imagina um orador tentando convencer uma platéia no tribunal de Atenas por meio de demonstrações em Barbara e Celarent, com terminologia técnica e sem apelo a nenhum exemplo, nenhuma imagem. Não é isso que se espera de um orador. Alguém que deles exigisse um discurso demonstrativo estaria exigindo o grau de acurácia inadequado ao objeto em questão.

O "ser humano cultivado", em contraste, é exatamente aquele que sabe qual é o grau adequado de acurácia que se deve exigir em cada contexto discursivo: de matemáticos, deve-se exigir demonstrações; mas, de oradores, deve-se exigir discursos persuasivos.

Logo após demarcar essa outra competência do ser humano cultivado, Aristóteles arremata com a seguinte observação:

cada um julga com acerto as coisas que conhece, e é dessas coisas que ele é um bom juiz. Assim, o ser humano cultivado em cada domínio particular é um bom juiz, e o ser humano cultivado a respeito de tudo é um bom juiz sem mais" (1094b27-1095a2, tradução minha).

Essa passagem é de difícil tradução, mas ela parece repetir a mesma idéia básica que já vimos no trecho inicial de As Partes dos Animais: 
no entanto, consideramos o ser humano cultivado como alguém que, sendo um só, é capaz de julgar a respeito de tudo, por assim dizer, ao passo que o outro [sc. o conhecedor do assunto] se ocupa com um domínio determinado; mas é que há outro tipo de ser humano cultivado, semelhante ao primeiro, mas em relação a algum domínio particular" (639a8-12).

Pois bem: assim como pode haver um ser humano cultivado apenas em certos domínios particulares (por exemplo, no domínio das ciências naturais), pode haver um ser humano cultivado em relação a todos os domínios. Nada indica que Aristóteles identifique este último com um erudito que dominasse o conteúdo completo de uma enciclopédia. Sua competência não tem por foco o valor de verdade das proposições básicas que compõem um dado domínio; portanto, tampouco depende de compreender exaustivamente o conteúdo de uma disciplina específica. No entanto, embora o ser humano cultivado em geral não se confunda com alguém dotado de conhecimento enciclopédico sobre todos os assuntos, é bem inverossímil que ele possa exercer sua competência em zoologia, por exemplo, sem dominar absolutamente nenhum conteúdo específico de zoologia. Ele deve conhecer ao menos alguns dados básicos da disciplina. Mesmo assim, sua aptidão para julgar sobre uma dada disciplina não depende de compreender exaustivamente o conteúdo específico da disciplina, mas depende de sua compreensão das regras aceitas no domínio, bem como de sua compreensão dos princípios silogísticos. O ser humano cultivado é alguém com a habilidade específica de avaliar, de modo apropriado, certos aspectos formais de qualquer disciplina. 


\section{Paideia e competência moral}

A função crítica da paideia também tem seu lugar no terreno da ética. Em Ethica Eudemia I.6, Aristóteles diz o seguinte:

Há alguns que - por haver a opinião de que compete ao filósofo não dizer nada a esmo, mas com explicação - muitas vezes, quando propõem explicações vazias e inapropriadas ao problema em questão, não são assim percebidos [...]. Ocorre que, com tais explicações, até mesmo homens experientes e capazes de agir são conquistados por aqueles que não sabem agir, nem são capazes de adquirir inteligência arquitetônica ou prática. Passam por isso devido à falta de formação: de fato, é falta de formação não ser capaz de discernir, a respeito de cada problema, quais explicações são apropriadas e quais são inapropriadas $(1216 \mathrm{~b} 40-1217 \mathrm{a} 10){ }^{27}$

A interpretação dessa passagem é bem controversa e muito depende de como se entende o termo "logos", que traduzi por "explicação". ${ }^{28}$ Minha proposta é a seguinte. Há a opinião correntemente aceita, com a qual Aristóteles mesmo concorda, de que é próprio do filósofo ser capaz de dar explicações. Mas alguns maus filósofos, ou charlatães, tiram proveito dessa opinião: propõem explicações inapropriadas para um dado problema, mas, como essas explicações não são detectadas como inapropriadas, eles conquistam até mesmo pessoas de experiência prática e capazes de agir. Estas últimas são as pessoas de excelência moral, isto é, dotadas da competência que as tornam capazes de agir corretamente de acordo com as demandas

27 A tradução é minha. Devo muito, neste ponto, às discussões sobre a Ethica Eudemia com Raphael Zillig (que há anos prepara a tradução dessa obra), Inara Zanuzzi e Fernando Mendonça.

28 Discuti essa passagem com detalhe em Angioni 2017. Para outra visão, ver Woods 1992, p. 59. Para o contexto mais geral dessa passagem, ver Karbowski 2015, p. 202-206; Mendonça 2017, Zillig 2017.

Filosofia e Educação [RFE] - Volume 9, Número 1 - Campinas, SP

Fevereiro-Maio de 2017 - ISSN 1984-9605 - p. 165-196 
morais de cada circunstância. Não fica claro em que consiste a conquista dessas pessoas pelos charlatães: ou os charlatães apenas conseguem angariar a falsa reputação de filósofos, ou bem conseguem convencer as pessoas de experiência prática a dar explicações despropositadas para suas ações. Mesmo no segundo caso, parece que não está em questão uma conquista que levasse as pessoas de excelência moral a agir de modo incorreto: a conquista se daria apenas no plano das razões e explicações, ou seja, as pessoas conquistadas pelos maus filósofos ou charlatães passariam a dar explicações inadequadas para as ações que praticam.

No entanto, para os propósitos deste artigo, basta notar o essencial: Aristóteles identifica como falta de formação (apaideusia) a incapacidade de discernir entre explicações apropriadas e explicações inapropriadas para determinado assunto (o que inclui, obviamente, explicações sobre por que se deve agir de tal e tal maneira em tais e tais circunstâncias). Por contraste dado que formação (paideia) e falta de formação (apaideusia) são contrários - se infere com segurança que a formação (paideia) seria ou envolveria precisamente a capacidade de discernir entre explicações apropriadas e explicações inapropriadas também no domínio da ética. Tal como a competência do ser humano cultivado, em As Partes dos Animais, não se confundia com o "conhecimento do assunto" em matéria de zoologia, de modo similar, na Ethica Eudemia, a competência do ser humano cultivado do ponto de vista moral não parece se confundir com a competência (hexis) que é a virtude do caráter, pela qual um ser humano se torna capaz de agir corretamente atendendo às demandas morais de cada circunstância particular. Talvez não seja exagero insistir em outra sugestão promissora. Tal como, em As Partes dos Animais, a competência do ser humano cultivado também envolvia a capacidade de apreciar o modo pelo qual a obra (As Partes dos Animais) deveria se desenvolver, de modo similar, na Ethica Eudemia, a competência do ser 
humano cultivado do ponto de vista moral parece envolver a capacidade de avaliar as explicações que serão propostas no decorrer da obra - por exemplo, a capacidade de julgar se a definição de eudaimonia proposta por Aristóteles é melhor (ou menos charlatã) do que as definições de "bem supremo" propostas por filosofias rivais. ${ }^{29}$

\section{O pepaideumenos e a "margem de erro"}

Outro aspecto da boa formação que caracteriza o "ser humano cultivado" consiste em um modo específico pelo qual ele desempenha suas habilidades de julgar e avaliar: Aristóteles codifica esse modo pelo uso do advérbio

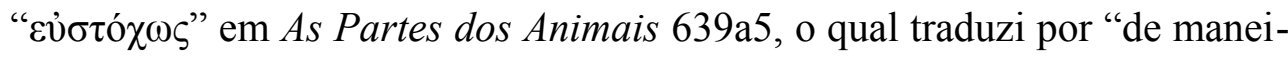
ra acertada", mas cujo sentido preciso é bem mais complexo e requer comentário.

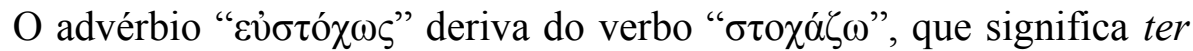
por alvo, atirar, acertar o alvo etc., mas que, em muitos usos, já indica intrinsecamente algum sucesso no ato de atirar. Esse verbo é usado por Aristóteles em contextos importantes de suas duas Éticas, e imprecisões a seu respeito podem levar a sérias incompreensões. ${ }^{30}$ No entanto, para os propósitos

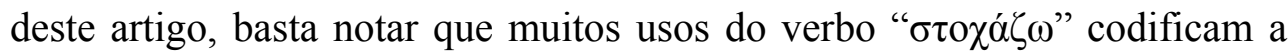
noção de um sucesso regular (ainda que não infalível) na ação de atirar em determinado alvo. Ou seja, esses usos do verbo descrevem a ação de quem regularmente mira determinado alvo e obtém sucesso em acertá-lo em um número significativo de vezes. O emprego do advérbio " $\varepsilon v ̉ \sigma \tau o ́ \chi \omega \varsigma$ ” em nos-

29 Para uma discussão sobre essa possível relação entre o trecho que examinamos e a seqüência da Ethica Eudemia, ver Zillig 2014.

30 A virtude do caráter é caracterizada como "stochastike tou mesou" em Ética a Nicômaco 1106b14-16: isso quer dizer que ela é uma aptidão pela qual acertamos o alvo (na maior parte das vezes, ao menos), que é o meson: nesse contexto, acertar o alvo consiste em agir bem considerando todos os fatores relevantes nas circunstâncias. Explorei mais o ponto em Angioni 2009, p. 54-55.

Filosofia e Educação [RFE] - Volume 9, Número 1 - Campinas, SP

Fevereiro-Maio de 2017 - ISSN 1984-9605 - p. 165-196 
sa passagem deriva desse uso do verbo. Uma boa sugestão seria traduzi-lo por expressões como "com uma significativa margem de acerto", "com uma boa pontaria". Tais expressões, no entanto, capturam apenas o aspecto estatístico da competência do "ser humano cultivado": ele acerta em boa parte de seus lances, mas pode também errar. No entanto, há ainda outro aspecto nessa competência. O sucesso regular do homem cultivado na ação de atirar em determinado alvo (isto é, na ação de emitir suas avaliações sobre propostas de explicação) depende da noção de sucesso competente, isto é, fruto de uma habilidade conquistada pelo exercício controlado. Essa habilidade é

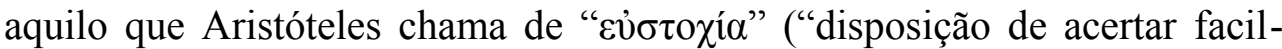
mente”) em Segundos Analíticos 89b10. O assunto preciso de Aristóteles

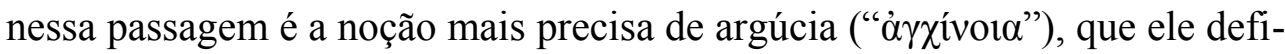
ne precisamente assim:

A argúcia consiste em certa disposição de acertar facilmente o termo mediador, em um tempo sem investigação" (89b10-11, tradução minha).

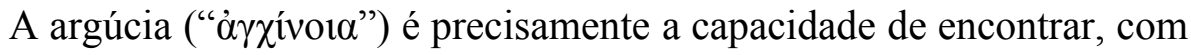
base em informações mínimas, sem demora e sem necessidade de muita reflexão, o termo mediador que explica uma determinada situação. O interesse de Aristóteles nessa capacidade é natural no contexto dos Segundos Analíticos, que se ocupam de uma teoria da explicação científica. Não fíca claro se a argúcia é um talento natural ou uma aptidão sedimentada pelo exercício

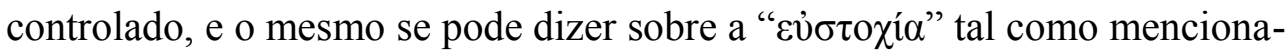
da em Segundos Analíticos 89b10-11. No entanto, a situação é outra no

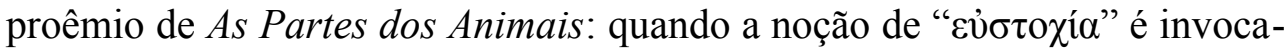
da na descrição das habilidades do "ser humano cultivado", não pode haver 
dúvida de que se trata de uma aptidão sedimentada pelo exercício, pois tais habilidades são apresentadas justamente como resultado final de um processo de educação. É importante ressaltar que a expressão grega para "ser humano cultivado" (isto é, para o ser humano que tem a competência denominada paideia), é o particípio perfeito do verbo "educar" na voz médio-passiva: assim, o pepaideumenos só pode ser alguém que adquiriu a paideia como resultado final de um processo e que mantém essa mesma paidéia

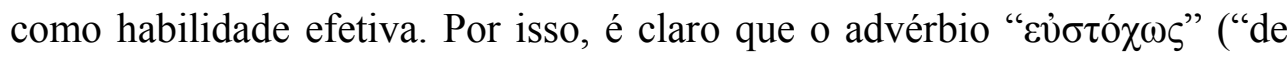
maneira acertada") tal como usado em 639a5 não se aplica a alguém que, sem treinamento sério, acerta o alvo na maioria das vezes, ou mesmo sempre, mas por puro acaso. Tal uso do advérbio se aplica precisamente a quem acerta o alvo na maioria das vezes devido a uma competência sedimentada por um processo de formação que envolve muito exercício. O ser humano cultivado pode errar, certamente, mas sua boa pontaria é precisamente fruto de sua competência. Seu acerto em suas avaliações é, como diria Sosa (2006), "completamente apto".

\section{Conclusão}

Qual é, no entanto, a relação entre o ser humano cultivado e o conhecedor de cada assunto? As competências do ser humano cultivado o tornam apto a apreciar o modo pelo qual explicações e exposições são apresentadas. No entanto, é possível que o ser humano cultivado não tenha nenhum conhecimento específico de nenhuma ciência?

A resposta que Aristóteles daria a esse pergunta é negativa. Em primeiro lugar, a distinção entre o ser humano cultivado e o conhecedor de cada assunto não é extensional, mas intensional. A distinção não corresponde a segmentos populacionais distintos, como se, por exemplo, os seres humanos cultivados fossem os membros de um departamento e os conhecedo-

Filosofia e Educação [RFE] - Volume 9, Número 1 - Campinas, SP

Fevereiro-Maio de 2017 - ISSN 1984-9605 - p. 165-196 
res do assunto fossem os membros de outro. A distinção é intensional: ela capta os fatores relevantes que correspondem a cada competência. Além do mais, nos textos em que atribui ao ser humano cultivado as competências que discutimos, Aristóteles jamais diz que as mesmas são incompatíveis com o conhecimento do assunto. Seu ponto é que as competências que cabem estritamente ao ser humano cultivado, enquanto tal, não dependem do conhecimento de assuntos determinados. Nada impede, porém, que o ser humano cultivado seja bem educado também em outros domínios e tenha conhecimento científico de um assunto específico. O próprio Aristóteles poderia ser indicado como exemplo de um mesmo indivíduo ao qual se poderiam atribuir ambas as competências. E Aristóteles reconhece que um mesmo geômetra - que é um "conhecedor do assunto" - pode sustentar dois tipos de argumentação (cf. APo 77a40-b15): enquanto geômetra, ele opera com as demonstrações que dependem dos princípios próprios da geometria e pode discutir qualquer proposição que dependa dos mesmos; é a isso que ele deve ater-se enquanto "conhecedor do assunto". No entanto, esse mesmo indivíduo pode discutir outras questões que não dependem dos princípios próprios da geometria, bem como pode discutir os próprios princípios. Ao fazê-lo, porém, ele não mais se comporta enquanto geômetra (cf. APo 77b5-7, 9-11). Se ele discute questões que dependem dos princípios silogísticos, ou de princípios comuns a toda ciência e a toda arte argumentativa, ele é ou "fillósofo" (cf. Física 185a20), ou "dialético" (cf. SE 170a36-39), ou, de acordo com o painel sugerido em As Partes dos Animais, um ser humano cultivado. ${ }^{31}$

Em segundo lugar, é bem claro que Aristóteles não considera que a paideia - a educação do ser humano - seja totalmente exaurida pela compe-

31 As relações entre filosofia e dialética receberam bastante atenção na literatura especializada; infelizmente, a mesma atenção não tem sido dado ao papel que o "ser humano cultivado" desempenha nesse quadro (uma exceção é Irwin 1988, p.27-29, 50, 145, 179-180). 
tência crítica que ele atribui ao ser humano cultivado no início de As Partes dos Animais. A paideia inclui outras competências. Sinal evidente disso é o cuidadoso uso da expressão na passagem inicial de As Partes dos Animais: "como que uma certa cultura" ("hoion paideian tina"). Se a competência que ele em seguida descreve e atribui ao ser humano cultivado é apenas uma certa cultura ou uma certa educação, é lícito inferir que há outras dimensões da educação que não foram contempladas nessa competência. E é bem claro, nesse sentido, que as ciências são, para Aristóteles, objeto de ensino. Já se entreteve até mesmo a tese de que a teoria da demonstração desenvolvida nos Segundos Analíticos ofereceria um modelo para a exposição didática de uma disciplina científica, do tutor para o discípulo apropriado (isto é, para o aluno já munido do pré-conhecimento requisitado). ${ }^{32}$ Há exageros nesse tese. ${ }^{33}$ Mas há algo que merece ser preservado: Aristóteles certamente concebe as disciplinas científicas como suscetíveis de ensino e, portanto, como componentes privilegiados de uma educação completa.

Assim, podemos concluir que uma educação completa - uma paideia completa, e não apenas "uma certa paideia" - envolve não apenas o aprendizado das disciplinas específicas, que nos torna conhecedores de seus respectivos assuntos, mas também envolve o aprendizado que termina com a consolidação das competências que Aristóteles descreve no início de $A s$ Partes dos Animais: a capacidade de avaliar, de modo certeiro, se explicações em um dado domínio se conformam às regras explanatórias que estão bem justificadas nesse domínio; a capacidade de discernir se uma exposição científica segue regras metodológicas adequadas e, enfim, a capacidade de discernir o tipo de argumentação que é apropriado a cada disciplina.

32 Essa é a tese clássica defendida por Barnes 1969. Para discussão da mesma, ver Angioni 2014 e Bronstein 2016.

33 Para discussão meticulosa desses exageros, ver Bronstein 2016, p. 31-42.

Filosofia e Educação [RFE] - Volume 9, Número 1 - Campinas, SP

Fevereiro-Maio de 2017 - ISSN 1984-9605 - p. 165-196 


\section{Referências bibliográficas}

ANGIONI, Lucas. (1999a). Aristóteles: As Partes dos Animais, Livro I. Cadernos de História e Filosofia da Ciência, v. 9, número especial.

. (1999b). "Princípio da não-contradição e semântica da predicação em Aristóteles", Analytica, vol. 4, n. 2, 1999b, pp. 121-58. - (2006). Introdução à Teoria da Predicação em Aristóteles. Campinas: Ed. Unicamp.

. (2009). "Em que sentido a virtude moral é mais exata do que a técnica? Notas sobre Ethica Nicomachea 1106b14-16", Dissertatio 29: 43-58.

- (2014). Demonstração, silogismo e causalidade. In: ANGIONI, L. (ed.), Lógica e Ciência em Aristóteles, Campinas: PHI, p. 61-120.

. (2017). "Explanation and method in Eudemian Ethics I.6". Archai 20, forthcoming.

BALME, David M. (1992). De Partibus Animalium I and De Generatione Animalium I, Oxford: Clarendon Press.

BARNES, Jonathan. (1969). "Aristotle's Theory of Demonstration", Phronesis 14: $123-52$.

BROADIE, Sarah, \& ROWE, Christopher. (2002). Aristotle: Nicomachean Ethics. Oxford: Oxford University Press.

BRONSTEIN, David. (2016). Aristotle on Knowledge and Learning. Oxford: Oxford UP.

CARBONE, Andrea. (2016). "The Axes of Symmetry: Morphology in Aristotle's Biology", Apeiron 49 (1): 1-31.

CHARLES, David. (2000). Aristotle on Meaning and Essence. Oxford: Oxford UP. CODE, Alan. (1986). "Aristotle's Investigation of a Basic Logical Principle: Which Science Investigates the Principle of Non-Contradiction?”, Canadian Journal of Philosophy, vol. 16, $\mathrm{n}^{\circ}$ 3, pp. 341-358.

COHEN, S. Marc. (1986). "Aristotle on the Principle of Non-Contradiction",

Filosofia e Educação [RFE] - Volume 9, Número 1 - Campinas, SP Fevereiro-Maio de 2017 - ISSN 1984-9605 - p. 165-196 
Canadian Journal of Philosophy, Vol. 16, nº 3, pp. 359-370.

COOPER, John. (1999). “Aristotle on the Authority of Appearances". In: Reason and Emotion, Princeton: Princeton

University Press.

FINE, Kit. (2012). “What is Metaphysics?”. In: TAHKO, T. (ed.), Contemporary Aristotelian Metaphysics, Cambridge: CUP, 8-25.

FURTH, Montgomery. (1986). "A Note on Aristotle's Principle of NonContradiction", Canadian Journal of Philosophy, v. 16, n. 3, p. 371-381.

GOLDIN, Owen. (2013). Circular justification and explanation in Aristotle. Phronesis 58, 195-214.

IRWIN, Terence. (1988). Aristotle's First Principles. Oxford: OUP. . (1999). Aristotle: Nicomachean Ethics, Indianapolis: Hackett.

KARBOWSKI, Joseph. (2015). "Phainomena as Witnesses and Examples: The Methodology of Eudemian Ethics 1.6", Oxford Studies in Ancient Philosophy 49, p. 193-226.

LEBLOND, Jean-Marie. (1945). Philosophie de la vie: le livre premier du traité sur Les Parties des Animaux, Paris: Vrin.

LENNOX, James. (1987). "Divide and explain: the Posterior Analytics in practice" in Gotthelf, A. \& Lennox J. (edd.), Philosophical Issues in Aristotle's Biology, Cambridge: Cambridge University Press, p. 90-119. . (2001). Aristotle: On The Parts of Animals I-IV, Oxford: Clarendon Press. . (2010). "The unity and purpose of On the Parts of Animals I", in Lennox, J. \& Bolton, R. (edd.), Being, Nature and Life in Aristotle, Cambridge: CUP, p. 5677.

LESHER, James H. 2010. Saphêneia in Aristotle: Clarity, Precision and Knowledge, Apeiron 43, p. 143-156.

Filosofia e Educação [RFE] - Volume 9, Número 1 - Campinas, SP Fevereiro-Maio de 2017 - ISSN 1984-9605 - p. 165-196 
LOURENÇO, Daniel. (2013). Definição, não-contradição e indemonstrabilidade dos princípios: uma proposta de leitura para Metafísica IV à luz de Segundos Analiticos I.22. Dissertação de mestrado, Universidade Federal de Santa Catarina.

MENDONÇA, Fernando M. (2014). “A utilidade dos Tópicos em relação aos princípios das ciências". In: ANGIONI, Lucas (ed.), Lógica e Ciência em Aristóteles, Campinas: PHI, pp. 287-330.

- (2017). "Does Aristotle have a dialectical attitude in EE I 6? A negative answer", Archai 20, forthcoming.

MOREIRA, Vivianne de Castilho. (2015). Observações sobre a estrutura da significação em Metafísica $\Gamma$ 4. Journal of Ancient Philosophy, 9(1), 22-40.

NUSSBAUM, Martha C. (1986). "Saving Aristotle's Appearances", in The Fragility of Goodness, Cambridge: Cambridge University Press, pp. 240-263.

SOSA, Ernst. (2006). A Virtue Epistemology. Apt Belief and Reflective Knowledge, Vol. 1. Oxford: OUP.

WOODS, Michael. (1992). Eudemian Ethics - Books I, II and VIII. Oxford: OUP. ZILLIG, Rafael. (2014). As relações entre o proêmio da Ética Eudêmia e o restante da obra: uma discussão a partir da análise de Ética Eudêmia I.7, Philósophos 19, n. 2, p. 221-243.

. (2017). “O que é 'verdadeiro, mas não esclarecedor' segundo a Ética Eudêmia", Archai 20, forthcoming. 